\title{
Role of Gated SPECT MPI in Follow-up of Patients after Coronary Revascularization
}

\author{
Azmal Kabir Sarker ${ }^{1}$, 2, Faria Nasreen ${ }^{3}$, Lutfun Nisa ${ }^{3}$ and Raihan Hussain ${ }^{4}$ \\ ${ }^{1}$ Institute of Nuclear Medicine and Allied Sciences, Mitford, SSMC campus, Dhaka, 1100. \\ ${ }^{2}$ Institute of Nuclear Medical Physics, AERE campus, Savar, Dhaka. \\ ${ }^{3}$ National Institute of Nuclear Medicine and Allied Sciences, BAEC, Bangabandhu Sheikh Mujib Medical University campus, Shahbag, Dhaka, 1000. \\ ${ }^{4}$ Department of Nuclear Medicine, Apollo Hospitals, Plot 81, Block E, Bashundhara R/A, Dhaka, 1229 \\ Correspondence Address: Azmal Kabir Sarker, Institute of Nuclear Medicine and Allied Sciences, Mitford, Dhaka, aksninmas @ gmail.com
}

\begin{abstract}
Objective: Gated SPECT myocardial perfusion imaging (GSMPI) is a preferred modality for non invasive assessment following coronary revascularization $(\mathrm{CR})$ of both symptomatic and asymptomatic patients. This study was conducted to observe the impact of GSMPI results on further management of patients who after CR had underwent GSMPI at National Institute of Nuclear Medicine and Allied Sciences (NINMAS). Patients and methods: Record files of GSMPI of all patients who underwent GSMPI over a period of 31 months from June 2011 to December 2013 at NINMAS for assessment of perfusion after CR were selected from the Nuclear Cardiology Divisional archive of patient studies in order to retrieve their clinical and demographic data including the contact numbers. The results of GSMPI scan were categorized as normal scan (NS) and perfusion defect (PD) which included reversible and/or fixed PD. All the contact numbers were called up by a nuclear medicine physician who conducted a semi-structured telephonic interview either with the patients or with a concerned family member. Management strategies adopted after GSMPI were categorized as conservative (CM) and interventional (IM).Cramer's V $(\varphi c)$ test were done to find strength of relation among patients' symptoms, scan findings and management strategies.

Results: Follow up data of 55 patients $(54 \mathrm{M}, 1 \mathrm{~F})$ among $68(66 \mathrm{M}, 2 \mathrm{~F})$ were available who underwent MPI for the purpose of post CR assessment. MPI was performed in between six months to 13 years after CR (mean $43.8 \pm 48.2$ months). Categorically 33 patients had percutaneous transluminal coronary angioplasty (PTCA) with stent, 16 patients had coronary artery by-pass grafting (CABG) and 6 patients had both CABG \& PTCA. There were 38 PD (27symptomatic) and 17 NS (12 symptomatic). Since all patients (n=12) who had fixed PD were symptomatic, a strong relation was found between being symptomatic and fixed perfusion defect $(\varphi \mathrm{c}>0.3)$. Symptoms were found to be weakly related with reversible PD i.e. ischemia $(\varphi c<0.2)$. Management strategies were conservative in 44 (30 symptomatic and 28 PD) and interventional in 11 (nine symptomatic and $10 \mathrm{PD}$ ). Management strategies were found to be weakly related with symptoms $(\varphi c<0.2)$ but moderately related with perfusion status $(\varphi \mathrm{c}=\mathbf{0 . 2 4})$.

Conclusions: While symptoms were observed to be poorly related with perfusion status following CR, GSMPI guided to choose further interventional management strategies with rationality in lower proportion of patients.

Key Words: Gated SPECT, Myocardial Perfusion Imaging (MPI), Coronary revascularization.

Bangladesh J. Nucl. Med. Vol. 22 No. 1 January 2019

Doi: https://doi.org/10.3329/bjnm.v22i1.40501
\end{abstract}

\section{INTRODUCTION}

While the sentinel role of gated SPECT myocardial perfusion imaging (GSMPI) to guide coronary revascularization $(\mathrm{CR})$ is established during past 40 years (1), restenosis has remained the Achilles hill of CR. Restenosis can be asymptomatic posing athreat to timely interventionor can be symptomatic with a long list of noncardiac etiology to exclude (2-4). In both the cases GSMPI is recommended as a tool for detection $(5,6)$ by virtue of its higher accuracy in comparison to exercise electrocardiogram $(7,8)$. GSMPI has been an associate to management of ischemic heart disease (IHD) in Bangladesh for past 20 years (9). It has been a general observation that the proportion of post CR patient referred for GSMPI has been progressively increasing at National Institute of Nuclear Medicine and Allied Sciences (NINMAS).This study was therefore conducted to observe the impact of GSMPI results on further management of patients who after CR had underwent GSMPI.

\section{PATIENTS AND METHODS}

\section{Subjects}

This is a cross sectional retrospective study conducted in August, 2016 on a group of patients who had underwent $\mathrm{CR}$ previously and then were referred to Nuclear Cardiology Division of NINMAS for assessment of post CR myocardial perfusion status from June of 2011 to December of 2013. Of the total number of selected patients fulfilling above criteria, the proportion whose responses were available during follow-up were included in the final analysis.

\section{Procedure of follow-up}

Patient data was obtained from the Nuclear Cardiology Divisional archive of patient studies. Status of 
revascularization was noted for each patient. The image and clinical record files of all patients who underwent GSMPI for post CR assessment within the defined study period were then selected and their contact information was retrieved. The contact numbers of patients were called up by a nuclear medicine physician in order to conduct a semi structured interview over telephone with either directly with the patients or with a concerned family member. Information regarding patient's health status as well as further management strategies adopted or advised by the cardiologist or cardiac surgeon within this duration was enquired.

\section{Categorization of variables and response}

The results of GSMPI scan retrieved from image archive were categorized as normal scan (NS) and perfusion defect (PD) which included reversible and/or fixed PD. Management strategies after GSMPI were categorized as conservative and interventional.

Descriptions of variables and analytic method

Continuous data were presented as means and standard deviations (SD) and value ranges. Categorical data were presented as frequencies and percentages. For test of association between patients' symptoms with scan findings and management strategies Chi-square test could not be adopted because there was no asymptomatic patient with fixed perfusion defect leaving count zero in a two by two table. This is why, Cramér's V $\left(\varphi_{c}\right)$ test was done to find strength of relation among patients' symptoms with scan findings and management strategies,
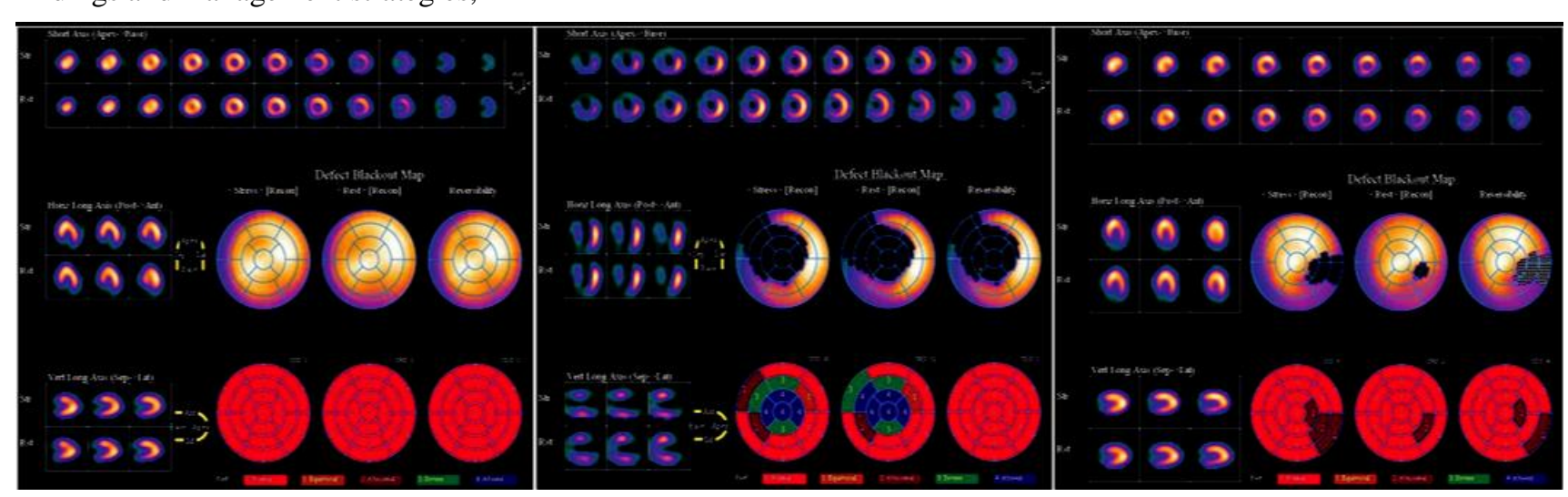

Figure 1: Representative post-stress and rest GS MPI images in post CR patients. There is (a) normal myocardial perfusion in a 67 years old male; (b) extensive fixed perfusion defect in LAD territory in a 50 years old male and (c) reversible perfusion defect in LCX territory in a 68 years old male. LV slices are displayed in three standard axes; perfusion map in 17 LV segments with perfusion scores displayed using 4DMSPECT 
territories, 10 had fixed defects in revascularized territories, seven had ischemia in previously non revascularized territories and two patients had fixed defect in previously non revascularized territory. Thus, as showed in Table 1, among the 38 patients with PD, the proportion of symptomatic versus asymptomatic was 27/11. Similarly among the 17 patients with NS the proportion of symptomatic versus asymptomatic was 12/5. Since all patients $(n=12)$ who had fixed PD were symptomatic, as showed in Table 2, being symptomatic was rather strongly related with finding of fixed PD $\left(\varphi_{c}>0.3\right)$ than NS or reversible PD. Conversely, being symptomatic was rather weakly related with finding of reversible PD i.e. ischemia $\left(\varphi_{c}<0.2\right)$ than NS.

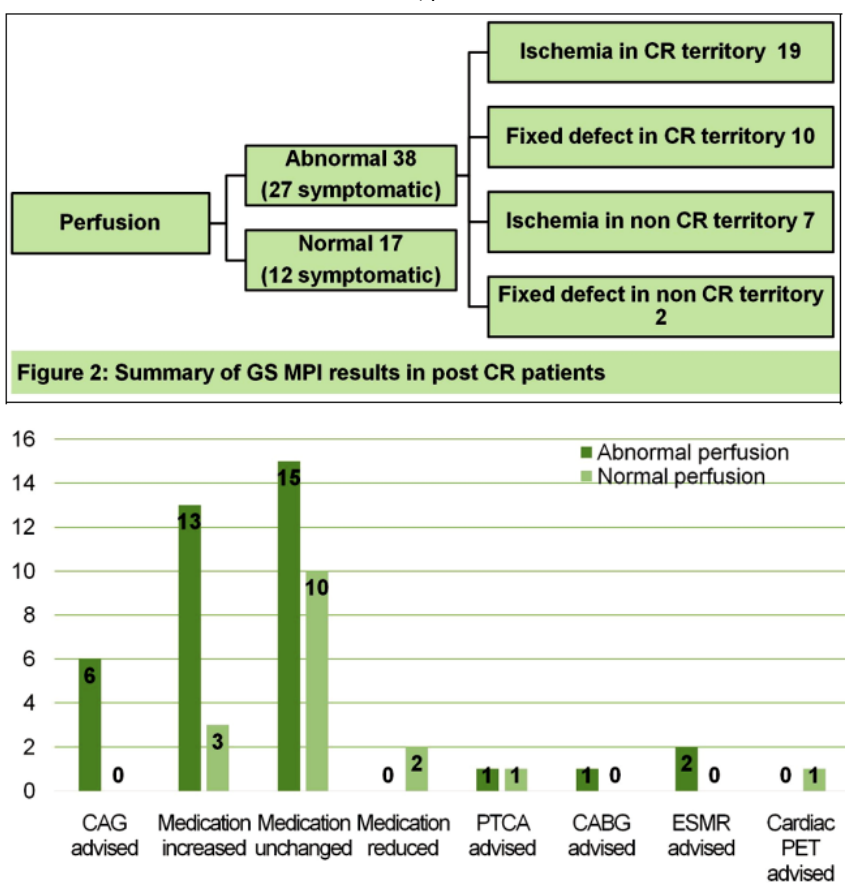

Figure 3: Follow up status of post CR patients after GS MPI

Management strategies and association with symptoms or perfusion status

Among the strategies undertaken by the clinicians (Figure 3) those categorized as conservative $(n=44)$ in this study were, regimen was kept unchanged in 25 $(\mathrm{PD} / \mathrm{NS}=15 / 10)$, extension or maximization of medication regimen was done in $16(\mathrm{PD} / \mathrm{NS}=13 / 3)$, reduction of medication regimen in two, both having NS (Table 3) and further work up advised with cardiac PET in one (NS). Management strategies, categorized as interventional $(\mathrm{n}=11)$ were advise for coronary angiogram (CAG) to six (all PD), advise for extracorporeal shock wave myocardial revascularization (ESMR) to two (both $\mathrm{PD})$, advise for further PTCA to two (PD/NS=1/1) and advise for CABG to one (PD) Thus among the 44 patients whose management strategies were conservative, the proportion of symptomatic versus asymptomatic was 30/14 (Table 4a) whereas proportion of PD versus NS and 28/16 (Table 4b). Similarly, among the 11 patients whose management strategies were interventional, the proportion of symptomatic versus asymptomatic was $9 / 2$ whereas proportion of PD versus NS was 10/1. The proportion of NS versus PD in patients who after GSMPI were advised with unchanged regimen were 10/15, curtailed regimen $2 / 0$ and extended regimen 3/13. Table 5 shows $\varphi_{c}$ values representing moderate to strong relation of change of medication regimen with perfusion status.

Finally, Table 6 shows that the management strategies were found to be weakly related with symptoms $\left(\varphi_{c}<0.2\right)$ but moderately related with perfusion status $\left(\varphi_{c}=0.24\right)$.

Table 1: Distribution of perfusion status according to presence of symptoms

\begin{tabular}{lccc}
\hline & Symptomatic & Asymptomatic & $\begin{array}{c}\text { \% of } \\
\text { patients }\end{array}$ \\
\hline $\begin{array}{l}\text { Normal perfusion } \\
\text { Total abnormal } \\
\text { perfusion }\end{array}$ & 12 & 5 & 0.71 \\
$\begin{array}{l}\text { Fixed perfusion } \\
\text { defect }\end{array}$ & 12 & 11 & 0.71 \\
$\begin{array}{l}\text { Reversible } \\
\text { perfusion defect }\end{array}$ & 15 & 11 & 0.58 \\
\hline
\end{tabular}

Table 2: Measure of association of perfusion status and symptoms

\begin{tabular}{lcc}
\hline Comparison & $\begin{array}{c}\text { Cramer's V } \\
\text { measure of association }\end{array}$ & $\mathrm{p}$ value \\
\hline Normal vs fixed perfusion defect & $\mathbf{0 . 3 8}$ & $\mathbf{0 . 0 3 9}$ \\
Reversible vs fixed perfusion defect & $\mathbf{0 . 4 3}$ & $\mathbf{0 . 0 0 8}$ \\
Normal vs reversible perfusion defect & 0.13 & 0.392 \\
Normal vs total abnormal perfusion defect & 0.01 & 0.97 \\
\hline
\end{tabular}

Table 3: Distribution of change of medication regimen according to perfusion status

\begin{tabular}{lcc}
\hline & Normal Perfusion & $\begin{array}{c}\text { Perfusion } \\
\text { Defect }\end{array}$ \\
\hline Unchanged regimen & 10 & 15 \\
Curtailed regimen & 2 & 0 \\
Extended regimen & 3 & 13 \\
\hline
\end{tabular}


Table 4 (a): Distribution of management strategies according to symptoms

\begin{tabular}{lcc}
\hline & Symptomatic & Asymptomatic \\
\hline $\begin{array}{l}\text { Conservative } \\
\text { management }\end{array}$ & 30 & 14 \\
$\begin{array}{l}\text { Interventional } \\
\text { management }\end{array}$ & 9 & 2 \\
\hline
\end{tabular}

Table 4 (b): Distribution of management strategies according to perfusion status

\begin{tabular}{lcc}
\hline & Normal perfusion & Perfusion defect \\
\hline $\begin{array}{l}\text { Conservative } \\
\text { management }\end{array}$ & 16 & 28 \\
$\begin{array}{l}\text { Interventional } \\
\text { management }\end{array}$ & 1 & 10 \\
\hline
\end{tabular}

Table 5: Measure of association of medication regimen according to perfusion status

\begin{tabular}{lcc}
\hline Comparison & $\begin{array}{c}\text { Cramer's V } \\
\text { measure of } \\
\text { association }\end{array}$ & p value \\
\hline Unchanged vs curtailed & 0.32 & 0.1 \\
Unchanged vs extended & 0.22 & 0.1 \\
Curtailedvs extended & 0.57 & 0.01 \\
\hline
\end{tabular}

Table 6: Measure of association of management strategy with symptoms and perfusion status

\begin{tabular}{lcc}
\hline Comparison & $\begin{array}{c}\text { Cramer's V } \\
\text { measure of } \\
\text { association }\end{array}$ & p value \\
\hline $\begin{array}{l}\text { Symptom vs } \\
\text { management }\end{array}$ & 0.12 & 0.37 \\
$\begin{array}{l}\text { Perfusion status } \\
\text { (PD/NS) vs management }\end{array}$ & 0.24 & 0.08 \\
\hline
\end{tabular}

\section{DISCUSSION}

Outcome of CR can be jeopardized by restenosis or in-stent restenosis following a percutaneous coronary intervention (PCI) due to neointimal proliferation as a result of neoatherosclerosis (2). Similarly, following a CABG, there can be endothelial damage within the venous grafts by the operative procedure and by the pulsatile high-pressure arterial flow, necessitating platelet deposition and thrombus formation (3).The reported incidences of restenosis after PTCA used to be $32-55 \%$ in the pre-stent era, dropping to $17-41 \%$ in the bare metal stent era followed by a further drop to $<10 \%$ with the advent of drug eluting stent (2). Post CABG patency at 10 years is reported to be $61 \%$ for venous grafts and $85 \%$ for arterial grafts (10).

Recurrent angina is a manifestation of restenosis or instent restenosis, which can arise from stretch pain, instent thrombosis, incomplete revascularization, progression of coronary atherosclerosis, coronary microvascular dysfunction, epicardial coronary spasm or even from a wide confounding array of non-cardiac causes (4,5). Seminal investigators (11-16) have shown that chest pain following PCI is a poor indicator of ischemia or restenosis and does not risk stratify patients whereas GSMPI does. Approximately $50 \%$ of patients remain asymptomatic when restenosis occurs (11-15). Conversely, up to $45 \%$ of patients developing chest pain after PCI do not have angiographic restenosis $(7,13,17$ 24). A large trial reported in 2005 finds that $42 \%$ of patients in the stent group and $22 \%$ in the CABG group have recurrence of symptoms requiring repeat revascularization after 5 years from an initial CR (25). In our series, proportion of symptomatic patient in groups with normal perfusion, fixed PD and reversible PD were $71 \%, 100 \%$ and $58 \%$ leading to the finding that symptoms were weakly related with scan finding of reversible PD i.e. ischemia $(\varphi c<0.2)$.

Current guidelines recognize that myocardial ischemia whether manifest or asymptomatic have a deleterious effect on prognosis (26-28). GSMPI out performs exercise electrocardiography for diagnosis of $>70 \%$ stenosis of aorto-coronary bypass grafts (8) as well as for the diagnosis of restenosis after coronary stenting (7, 16, 27).Sensitivity and specificity of MPI, performed at varying times after PCI range from $39 \%$ to $100 \%$ and $46 \%$ to $100 \%$ respectively $(7,13,17-24)$, improving with time since revascularization $(7,13,18,20-24)$. Giedd and Bergmann recommend MPI in asymptomatic patients at six to nine months following PCI and propose to limit angiography in patients who will have medium or large defects or scan feature of stress induced left ventricular failure (29). Zellweger et al recommend post CABG follow-up with GSMPI in patients with symptoms before 
5 years of $\mathrm{CR}$ and in all patients irrespective of symptoms after 5 years CR. (6)

\section{Limitations of the study}

Association of post CR perfusion status with gender and with patients' compliance to medical treatment and/or advice to lifestyle modification could not be statistically analyzed. Rationality of variation of medical management strategy in response to GSMPI findings was not addressed.

\section{CONCLUSIONS}

This study could find poor relation between cardiac symptoms and myocardial perfusion status in patients following CR where GSMPI could guide a rational choice between conservative management in greater proportion of patients while directing the smaller proportion of patients towards further interventional management. Thus it may be permitted to assume that GSMPI in this series played an extended role as a gate keeper to invasive management in status post CR patients, in addition to its otherwise popular role of guiding initiation of $\mathrm{CR}$.

\section{DISCLOSURE}

No competing financial interests exist

\section{ACKNOWLEDGEMENT}

Authors acknowledge the collaborative contribution of cardiologists and cardiac surgeons to Nuclear Cardiology.

\section{REFERENCES}

1. Bourque JM, Beller GA. Stress Myocardial Perfusion Imaging for Assessing Prognosis: An Update JACC Cardiovasc Imaging 2011;4:1305-19doi: 10.1016/j.jcmg.2011.10.003

2. Buccheri D, Piraino D, Andolina G, Cortese B. Understanding and managing in-stent restenosis: a review of clinical data, from pathogenesis to treatment. $\mathrm{J}$ Thorac Dis.2016;8(10):E1150-62.doi: 10.21037/jtd.2016.10.93

3. Li R, Lan B, Zhu T, Yang Y, Cai M, Fang Z et al. Preventing graft restenosis after coronary artery bypass grafting with tissue-type plasminogen activator. Eur J Med Res. 2017; 22: 18.doi: 10.1186/s40001-017-0259-8

4. Abbate A, Biondi-Zoccai GG, Agostoni P, Lipinski MJ, Vetrovec GW. Recurrent angina after coronary revascularization: a clinical challenge. Eur Heart J. 2007;28(9):1057-65.doi: 10.1093/eurheartj/eh1562
5. Izzo P, Macchi A, De Gennaro L, Gaglione A, Di Biase M, Brunetti ND. Recurrent angina after coronary angioplasty: mechanisms, diagnostic and therapeutic options. Eur Heart J Acute Cardiovasc Care. 2012; 1(2): 158-69. doi: 10.1177/2048872612449111

6. Zellweger MJ, Lewin HC, Lai S, Dubois EA, Friedman JD, Germano $G$ et al. When to stress patients after coronary artery bypass surgery? Risk stratification in patients early and late postCABG using stress myocardial perfusion SPECT: implications of appropriate clinical strategies. J Am Coll Cardiol.

2001;37(1):144-52.doi:10.1016/S0735-1097(00)01104-9

7. Galassi AR, Foti R, Azzarelli S, Coco G, Condorelli G, Russo G et al. Usefulness of exercise tomographic myocardial perfusion imaging for detection of restenosis after coronary stent implantation. Am J Cardiol. 2000; 85(11): 1362-4.doi: 10.1016/S0002-9149(00)00770-0

8. Carballo J, Candell-Riera J, Aguadé-Bruix S, Castell-Conesa J, Larrousse E, Domingo E et al. Diagnostic accuracy of tomographic myocardial imaging for evaluation of aortocoronary graft patency.[Article in Spanish]. Rev Esp Cardiol 2000;53(5):6116.PMID: 10816168

9. Nasreen F, Nisa L, Sarker AK, Kabir MF. Journey of Nuclear Cardiology in Bangladesh - A report. Bangladesh J Nucl Med 2009;12(1):108

10. Goldman S, Zadina K, Moritz T, Ovitt T, Sethi G, Copeland JG et al. Long-term patency of saphenous vein and left internal mammary artery grafts after coronary artery bypass surgery: results from a Department of Veterans Affairs Cooperative Study. J Am Coll Cardiol.2004;44(11):2149-56.doi: 10.1016/j.jacc.2004.08.064

11. Holmes DR Jr, Vlietstra RE, Smith HC, Vetrovec GW, Kent KM, Cowley MJ et al. Restenosis after percutaneous transluminal coronary angioplasty (PTCA): a report from the PTCA Registry of the National Heart, Lung, and Blood Institute. Am J Cardiol 1984;53(12):77C-81C.doi:10.1016/0002-9149(84)90752-5

12. Nobuyoshi M, Kimura T, Nosaka H, Mioka S, Ueno K, Yokoi H et al. Restenosis after successful percutaneous coronary angioplasty: serial angiographic follow-up of 229 patients. J Am Coll Cardiol 1988;12(3):616-23.doi:10.1016/s0735-1097(88)80046-9

13. Hecht HS, Shaw RE, Chin HL, Ryan C, Stertzer SH, Myler RK. Silent ischemia after coronary angioplasty: evaluation of restenosis and extent of ischemia in asymptomatic patients by tomographic thallium-201 exercise imaging and comparison with symptomatic patients. J AmColl Cardiol 1991;17(3):670-7. doi:10.1016/s0735-1097(10)80183-4

14. Hernández RA, Macaya C, Iñiguez A, Alfonso F, Goicolea J, Fernandez-Ortiz Aet al. Midterm outcome of patients with asymptomatic restenosis after coronary balloon angioplasty. J Am Coll Cardiol 1992;19(7):1402-9.doi:10.1016/0735-1097(92)90594-d

15. Ruygrok PN, Webster MW, de Valk V, van Es GA, Ormiston JA, Morel MA et al. Clinical and angiographic factors associated with asymptomatic restenosis after percutaneous coronary intervention. Circulation 2001;104(19):2289-94.doi:10.1161/hc4401.098294

16. Legrand V, Raskinet B, Laarman G, Danchin N, Morel MA, Serruys PW. Diagnostic value of exercise electrocardiography and angina after coronary artery stenting. Am Heart J 1997;133(2):2408.https:// doi.org/10.1016/S0002-8703(97)70214-X 
17. Califf RM, Fortin DF, Frid DJ, Harlan WR 3rd, Ohman EM, Bengtson JR et al. Restenosis after coronary angioplasty: an overview. J Am Coll Cardiol 1991;17(6Suppl B):2B-13B .doi:10.1016/0735-1097(91)90933-Z

18. Marie PY, Danchin N, Karcher G, Grentzinger A, Juillière Y, Olivier Pet al.Usefulness of exercise SPECT-thallium to detect asymptomatic restenosis in patients who had angina before coronary angioplasty. Am Heart J 1993;126(3 pt 1):571-7.doi:10.1016/0002-8703(93)90406-y

19. Miller DD, Verani MS. Current status of myocardial perfusion imaging after percutaneous transluminal coronary angioplasty. J Am Coll Cardiol 1994;24(1):260-6.doi:10.1016/0735-1097(94)90572-х

20. Milan E, Zoccarato O, Terzi A,Ettori F, Leonzi O, Niccoli Let al. Technetium-99m-sestamibi SPECT to detect restenosis after successful percutaneous coronary angioplasty. J Nucl Med 1996;37(8):1300-5.PMID: 8708760

21. Kósa I, Blasini R, Schneider-Eicke J,Neumann FJ, Matsunari I, Neverve Jet al. Myocardial perfusion scintigraphy to evaluate patients after coronary stent implantation. J Nucl Med 1998;39(8):1307-11.PMID: 9708498

22. Milavetz JJ, Miller TD, Hodge DO, Holmes DR, Gibbons RJ. Accuracy of single-photon emission computed tomography myocardial perfusion imaging in patients with stents in native coronary arteries. Am J Cardiol 1998;82(7):857-61.doi:10.1016/s0002-9149(98)00492-5

23. Caner B, Oto A, Ovunc K, Kiratli P. Prediction of restenosis after successful percutaneous coronary angioplasty by dobutamine thallium-201 scintigraphy. Int $\mathrm{J}$ Cardiol 1998;66:175-81. doi:10.1016/s0167-5273(98)00217-4

24. Beygui F, Le Feuvre C, Maunoury C, Helft G, Antonietti T, Metzger JP et al. Detection of coronary restenosis by exercise electrocardiography thallium-201 perfusion imaging and coronary angiography in asymptomatic patients after percutaneous transluminal coronary angioplasty. Am J Cardiol 2000;86(1): 35-40. doi:10.1016/s0002-9149(00)00825-0
25. Serruys PW, Ong AT, van Herwerden LA, Sousa JE, Jatene A, Bonnier JJ et al. Five-year outcomes after coronary stenting versus bypass surgery for the treatment of multivessel disease: the final analysis of the Arterial Revascularization Therapies Study (ARTS) randomized trial. J Am Coll Cardiol. 2005;46(4):575-81.doi: 10.1016/j.jacc.2004.12.082

26. Smith SC, Dove JT, Jacobs AK, Kennedy JW, Kereiakes D, Kern $\mathrm{MJ}$ et al. ACC/AHA guidelines for percutaneous coronary intervention: a report of the American College of Cardiology/American Heart Association Task Force on Practice Guidelines (Committee to Revise the 1993 Guidelines for Percutaneous Transluminal Coronary Angioplasty). J Am Coll Cardiol 2001;37(8): 2215-38. doi:10.1016/S0735-1097(01)01344-4

27. Gibbons RJ, Balady GJ, Beasley JW, Bricker JT, Duvernoy WF, Froelicher VF et al. ACC/AHA Guidelines for Exercise Testing. A report of the American College of Cardiology/American Heart Association Task Force on Practice Guidelines (Committee on exercise Testing). J Am Coll Cardiol 1997;30(1):260-315. doi:10.1016/S0735-1097(97)00150-2

28. Ritchie JL, Bateman TM, Bonow RO, Crawford MH, Gibbons RJ, Hall $\mathrm{RJ}$ et al. ACC/AHA Guidelines for clinical use of cardiac radionuclide imaging: a report of the American Heart Association/American College of Cardiology Task Force on Assessment of Diagnostic and Therapeutic Cardiovascular Procedures (Committee on Radionuclide Imaging), developed in collaboration with the American Society of

Nuclear Cardiology. JAm Coll Cardiol 1995;25(2):521-47. https://doi.org/10.1016/0735-1097(95)90027-6

29. Geidd KN, Bergmann SR. Myocardial perfusion imaging following perctaneous coronary intervention: the importance of restenosis, se progression, and directed reintervention. J Am Coll Cardiol 2004; 43(3):328-36.doi: 10.1016/j.jacc.2003.09.032 